\title{
Characterization of Room-Temperature Ionic Liquids by the Abraham Model with Cation-Specific and Anion-Specific Equation Coefficients
}

\author{
Laura Sprunger, ${ }^{\dagger}$ Michael Clark,,${ }^{\ddagger}$ William E. Acree Jr., ${ }^{* \dagger}$, and Michael H. Abraham ${ }^{\S}$ \\ Department of Chemistry, University of North Texas, P.O. Box 305070, Denton, Texas 76203-5070, \\ Department of Research and Statistical Support, University of North Texas, P.O. Box 305398, \\ Denton, Texas 76203-5398, and Department of Chemistry, University College London, 20 Gordon Street, \\ London WC1H 0AJ, U.K.
}

Received January 31, 2007

\begin{abstract}
Gas-to-RTIL (room-temperature ionic liquid) partition coefficients have been compiled for 592 different solute-RTIL combinations. These partition coefficients were converted into water-to-RTIL partition coefficients using the corresponding gas-to-water partition coefficients. Both sets of partition coefficients were analyzed using the Abraham solvation parameter model with cation-specific and anion-specific equation coefficients. The derived equations correlated the experimental gas-to-RTIL and water-to-RTIL partition coefficient data to within 0.10 and $0.14 \log$ units, respectively. The 8 sets of calculated cation-specific equation coefficients and 4 sets of calculated anion-specific equation coefficients can be combined to yield expressions capable of predicting the partition coefficients of solutes in 32 different RTILs.
\end{abstract}

\section{INTRODUCTION}

Room-temperature ionic liquids (RTILs) have become an increasingly popular solvent choice in the past decade as a reaction media for synthesis of potential new pharmaceutical drug molecules, biomolecules, and polymers, ${ }^{1-3}$ as reservoirs for the controlled release of drug molecules in pharmaceutical formulations ${ }^{4}$ and as an extraction solvent for the removal of sulfur compounds ${ }^{5}$ and organic contaminants from petroleum crude oils and soil samples, ${ }^{6}$ respectively. Immiscibility of ionic liquids with supercritical carbon dioxide, linear hydrocarbons, and several acyclic organic solvents makes RTILs ideally suited for synthetic preparations involving biphasic catalysis. $^{7}$ Most (if not all) of these synthetic methods have been performed in RTILs. Much higher product yields and shorter reaction times were reported for RTILs than for the more conventional organic solvents.

Currently synthetic procedures are known for making more than 200 different RTILs. ${ }^{8}{ }^{8}$ Considerable time and effort is devoted to developing ionic liquids having specific solvent characteristics. From a theoretical standpoint it should be possible to control and modify the physical properties (viscosity, density, conductivity) and solubilibizing properties (hydrophobicity, hydrophilicity, hydrogen-bonding character) of RTILs by employing different cation-anion combinations. Our understanding of RTILs has not reached the point where this goal is realized.

Several recent papers have reported mathematical expressions for correlating and estimating infinite dilution activity coefficients and partition coefficients in select RTILs. Eike et al. ${ }^{10}$ proposed quantitative structure - property relationship (QSAR) correlations for the published infinite dilution

\footnotetext{
* Corresponding author e-mail: acree@unt.edu.

$\dagger$ Department of Chemistry, University of North Texas.

$\doteqdot$ Department of Research and Statistical Support, University of North Texas.

$\S$ University College London.
}

activity of organic solutes in 4-methyl-N-butylpyridinium tetrafluoroborate ([BMPy $\left.]^{+}\left[\mathrm{BF}_{4}\right]^{-}\right), 1$-methyl-3-ethylimidazolium bis(trifluoromethylsulfonyl)imide $\left([\mathrm{MEIm}]^{+}\left[\left(\mathrm{Tf}_{2} \mathrm{~N}_{2}\right]^{-}\right)\right.$, and 1,2-dimethyl-3-ethylimidazolium bis(trifluoromethylsulfonyl)imide $\left(\left[\mathrm{M}_{2} \mathrm{EIm}\right]^{+}\left[(\mathrm{Tf})_{2} \mathrm{~N}\right]^{-}\right)$at $298 \mathrm{~K}$ that had squared correlation coefficients ranging from $R^{2}=0.952$ to $R^{2}=$ 0.975. Tämm and Burke ${ }^{11}$ later reanalyzed the experimental data and reported three-parameter correlations based on molecular descriptors obtained using CODESSA PRO software. The authors' three-parameter correlations described the published experimental data to within standard errors from $\mathrm{SE}=0.30$ to $\mathrm{SE}=0.35 \log$ units. Acree, Abraham, and co-workers reported mathematical correlations based on the general Abraham solvation parameter model for the gas-tosolvent, $K$, and water-to-solvent partition coefficients, $P$, for ten different anhydrous RTILs ${ }^{12-14}$ and for two practical water-to-RTIL partition systems. ${ }^{15}$ The ten anhydrous waterto-RTIL correlations describe "hypothetical" partitions, and the partition coefficient is calculated as a molar solubility ratio for the solute dissolved in both neat solvents. Practical partitions, on the other hand, represent true equilibrium solute partitioning between the water-saturated organic phase and an aqueous phase that is saturated with the organic solvent. Correlations derived from the Abraham model described the experimental $\log K$ and $\log P$ data for 10 RTILs to within average standard deviations of $\pm 0.086 \log$ units and \pm 0.129 $\log$ units, respectively. The quoted values represent the average value of the standard deviations of the individual $\log K$ and $\log P$ correlations of the 10 RTILs.

The drawback in using QSAR and linear free energy relationship (LFER) models is that a separate equation must be derived for each RTIL solvent studied. There is no transfer of knowledge from one ionic liquid to the next. To address this problem we have devised a method for separating the five individual solvent coefficients in the Abraham model into cation-specific and anion-specific values that would 
apply to all RTILs containing the given cation and/or anion. While we illustrate our method with the Abraham model, there is no reason that the same methodology could not be applied to other QSAR and LFER models. Our method of separation of solute-cation and solute-anion contributions, if successful, allows us to construct the database for regression analyses by combining experimental partition coefficient for several different RTILs. The only restriction is that each cation and anion should appear in more than one RTIL. Our approach lets us utilize experimental data that would otherwise be unusable with the current method of obtaining Abraham model correlations for RTILs. Moreover, once the cation-specific and anion-specific equation coefficients are calculated, new predictive equations can be written simply by summing the known values. As a result, estimation of gas-to-RTIL and water-to-RTIL partition coefficients can be made for solutes dissolved in an ionic liquid for which there is insufficient experimental data to develop a RTIL-specific Abraham model correlation.

\section{EXPERIMENTAL METHODS}

Most of the experimental data that we were able to retrieve from the published literature ${ }^{16-52}$ pertained either to the infinite dilution activity coefficient, $\gamma_{\text {solute }}{ }^{\infty}$, or Henry's law constants, $K_{\text {Henry }}$, for solutes dissolved in RTILs. In order to apply the Abraham model the infinite dilution activity coefficients and Henry's law constants need to be converted to $\log K$ values for gas to ionic liquid partition through eqs 1 and 2

$$
\begin{gathered}
\log K=\log \left(\frac{R T}{\gamma_{\text {solute }}{ }^{\infty} \mathrm{VP}_{\text {solute }}{ }^{\mathrm{o}} V_{\text {solvent }}}\right) \\
\log K=\log \left(\frac{R T}{K_{\text {Henry }} V_{\text {solvent }}}\right)
\end{gathered}
$$

or to $\log P$ values for partition from water to the ionic liquid through eq 3

$$
\log P=\log K-\log K_{\mathrm{w}}
$$

In eqs 1 and 2, $R$ is the universal gas constant, $T$ is the system temperature, $\mathrm{VP}_{\text {solute }}{ }^{\mathrm{o}}$ is the vapor pressure of the solute at $T$, and $V_{\text {solvent }}$ is the molar volume of the solvent. The calculation of $\log P$ requires knowledge of the solute's gasphase partition coefficient into water, $K_{\mathrm{w}}$, which is available for most of the solutes being studied.

We have provided Excel spreadsheets (see the Supporting Information) that contain the partition coefficient data for the 584 different solute-RTIL combinations. The database has $\log K$ and $\log P$ values for solutes dissolved in 4-methylN-butylpyridinium tetrafluoroborate $\left([\mathrm{BMPy}]^{+}\left[\mathrm{BF}_{4}\right]^{-}\right), 1$-methyl-3-ethylimidazolium bis(trifluoromethylsulfonyl)imide $\left([\mathrm{MEIm}]^{+}\left[(\mathrm{Tf})_{2} \mathrm{~N}\right]^{-}\right)$, , 1,2-dimethyl-3-ethylimidazolium bis(trifluoromethylsulfonyl)imide $\left(\left[\mathrm{M}_{2} \mathrm{EIm}\right]^{+}\left[(\mathrm{Tf})_{2} \mathrm{~N}\right]^{-}\right)$, 1-methyl-3-butylimidazolium bis(trifluoromethylsulfonyl)imide$\left([\mathrm{MBIm}]^{+}\left[(\mathrm{Tf})_{2} \mathrm{~N}\right]^{-}\right)$, 1-methyl-3-hexylimidazolium bis(trifluoromethylsulfonyl)imide ([MHIm $\left.]^{+}\left[(\mathrm{Tf})_{2} \mathrm{~N}\right]^{-}\right)$, trimethylbutylammonium bis(trifluoromethylsulfonyl)imide $\left(\left[\mathrm{M}_{3} \mathrm{BAm}\right]^{+}\right.$$\left.\left[(\mathrm{Tf})_{2} \mathrm{~N}\right]^{-}\right)$, 1-methyl-3-octylimidazolium tetrafluoroborate ([MOIm $\left.]^{+}\left[\mathrm{BF}_{4}\right]^{-}\right)$, 1-methyl-3-butylimidazolium hexafluorophosphate $\left([\mathrm{MBIm}]^{+}\left[\mathrm{PF}_{6}\right]^{-}\right)$, 1-methyl-3-ethylimidazolium ethylsulfate $\left([\mathrm{MEIm}]^{+}\left[\mathrm{EtSO}_{4}\right]^{-}\right)$, 1-butyl-3-methylimidazolium tetrafluoroborate $\left([\mathrm{BMIm}]^{+}\left[\mathrm{BF}_{4}\right]^{-}\right), \mathrm{N}$-ethylpyridinium bis(trifluoromethylsulfonyl)imide ([NEPy $]^{+}\left[\left(\mathrm{Tf}_{2} \mathrm{~N}\right]^{-}\right)$, 1-methyl-3-hexylimidazolium tetrafluoroborate $\left([\mathrm{MHIm}]^{+}\left[\mathrm{BF}_{4}\right]^{-}\right)$, 1-methyl-3-ethylimidazolium tetrafluoroborate $\left([\mathrm{MEIm}]^{+}\right.$$\left[\mathrm{BF}_{4}\right]^{-}$), 1-methyl-3-octylimidazolium bis(trifluoromethylsulfonyl)imide $\left([\mathrm{MOIm}]^{+}\left[(\mathrm{Tf})_{2} \mathrm{~N}\right]^{-}\right)$, 1-methyl-3-hexylimidazolium hexafluorophosphate $\left([\mathrm{MHIm}]^{+}\left[\mathrm{PF}_{6}\right]^{-}\right)$, and 4-methyl-N-butylpyridinium bis(trifluoromethylsulfonyl)imide $\left([\mathrm{BMPy}]^{+}\left[(\mathrm{Tf})_{2} \mathrm{~N}\right]^{-}\right)$at $298 \mathrm{~K}$. Note that the water-to-RTIL $\log P$ values represent hypothetical partitions. Even so the values are still quite useful. Values of the hypothetical partition coefficients can be used to calculate infinite dilution activity coefficients and the solubilities for solutes dissolved in pure RTILs.

For the analysis of data, we have modified the two linear free energy equations of the Abraham solvation parameter model $^{12-15,53-56}$

$$
\begin{aligned}
& \log P=c+e \cdot \mathbf{E}+s \cdot \mathbf{S}+a \cdot \mathbf{A}+b \cdot \mathbf{B}+v \cdot \mathbf{V} \\
& \log K=c+e \cdot \mathbf{E}+s \cdot \mathbf{S}+a \cdot \mathbf{A}+b \cdot \mathbf{B}+l \cdot \mathbf{L}
\end{aligned}
$$

by rewriting each of the six solvent equation coefficients ( $e$, $s, a, b, v$, and $l)$ as

$$
\begin{array}{r}
\log P=c+\left(e_{\text {cation }}+e_{\text {anion }}\right) \cdot \mathbf{E}+\left(s_{\text {cation }}+s_{\text {anion }}\right) \cdot \mathbf{S}+ \\
\left(a_{\text {cation }}+a_{\text {anion }}\right) \cdot \mathbf{A}+\left(b_{\text {cation }}+b_{\text {anion }}\right) \cdot \mathbf{B}+ \\
\left(v_{\text {cation }}+v_{\text {anion }}\right) \cdot \mathbf{V}
\end{array}
$$

$$
\begin{array}{r}
\log K=c+\left(e_{\text {cation }}+e_{\text {anion }}\right) \cdot \mathbf{E}+\left(s_{\text {cation }}+s_{\text {anion }}\right) \cdot \mathbf{S}+ \\
\left(a_{\text {cation }}+a_{\text {anion }}\right) \cdot \mathbf{A}+\left(b_{\text {cation }}+b_{\text {anion }}\right) \cdot \mathbf{B}+ \\
\left(l_{\text {cation }}+l_{\text {anion }}\right) \cdot \mathbf{L}
\end{array}
$$

a summation of their respective cation and anion contributions. Equations 4 and 6 apply to solute transfer between two condensed phases (i.e., $\log P$ ), while eqs 5 and 7 involve solute transfer from the gas phase (i.e., $\log K$ ). The dependent variables in eqs $4-7$ are the solute descriptors as follows: $\mathbf{E}$ and $\mathbf{S}$ refer to the excess molar refraction in units of $\left(\mathrm{dm}^{3}\right.$ $\left.\mathrm{mol}^{-1}\right) / 10$ and dipolarity/polarizability descriptors of the solute, respectively, $\mathbf{A}$ and $\mathbf{B}$ are measures of the solute hydrogen-bond acidity and hydrogen-bond basicity, $\mathbf{V}$ is the McGowan volume in units of $\left(\mathrm{dm}^{3} \mathrm{~mol}^{-1}\right) / 100$, and $\mathbf{L}$ is the logarithm of the gas-hexadecane partition coefficient at 298 $\mathrm{K}$. The numerical value of $\mathbf{E}$ is obtained from the refractive index of the pure liquid compound at $293 \mathrm{~K}$; if the compound is a gas or solid, then the refractive index can be estimated or $\mathbf{E}$ itself can be calculated quite easily. ${ }^{57}$ The descriptors $\mathbf{S}, \mathbf{A}, \mathbf{B}$, and $\mathbf{L}$ are obtained from gas-liquid chromatographic measurements, water-to-solvent partition measurements, and solubility data as described in detail elsewhere ${ }^{53,58-61}$ The McGowan descriptor $\mathbf{V}$ is calculated from the atomic sizes and number of bonds in the molecule. ${ }^{62}$

We have also tabulated in the Excel spreadsheets (see Supporting Information) the solute descriptors for all of the solute molecules considered in the present study. The values are arranged in a 62 column $\times 584$ row matrix $(\log K)$ and a 62 column $\times 571$ row matrix $(\log P)$ by RTIL. The 62 columns are labeled according to ion-equation coefficient (e.g., $e_{\text {MEIm }}, s_{\text {MEIm }}, \ldots, \log K$ or $\log P$ ), and each row corresponds to one of the different solute-RTIL combinations. 
The solute descriptors are entered into the matrices under the appropriate column headings for the cation and anion in the RTIL in which the experimental partition coefficient was measured. Zeroes were placed in the cells for all other cations and anions not in the given RTIL. Both data matrices are in the form needed for our least-squares regression analyses.

We make a few additional comments concerning the computational methodology that will be employed in this study. The cation-specific and anion-specific coefficients in eqs 6 and 7 are paired. Each cation-specific coefficient goes together with its anion-specific counterpart to make up a summed value that the five solute descriptors are multiplied by. If one were to perform a regression analysis on eq 6 (or eq 7), then the statistical software would generate numerical equation coefficients based on some reference point. The reference point would likely depend on the particular database used and the software's built-in convergence routine. Calculation of additional ion values at some later time would be difficult as there would be no guarantee that the next regression analysis would find the same reference point. The simplest method that we know for getting the same reference point for all future analyses would be for us to mathematically set the equation coefficients for one ion equal to zero. Equation coefficients for all other ions would then be calculated relative to our fixed values. Theoretically it should not matter which ion we make as the point reference. We will set the anion-specific equation coefficient of $\left[(\mathrm{Tf})_{2} \mathrm{~N}\right]^{-}$equal to zero in all regression analyses performed in this study. If the RTIL contains the $\left[(\mathrm{Tf})_{2} \mathrm{~N}\right]^{-}$anion, then the calculated $\log P$ and $\log K$ values will only use five cation-specific equation coefficients for the cation present in the ionic liquid. In many respects our fixed reference point is analogous to how the chemical potentials of the individual ions are determined. By convention the chemical potential of the hydrogen ion is defined to be zero, and the values of all other ions are computed relative to this defined thermodynamic reference state.

\section{RESULTS AND DISCUSSION}

The 584 experimental $\log K$ values were analyzed collectively by regression analysis to yield the following correlation

$$
\begin{gathered}
\log K=c+\sum_{\text {cation }}\left(e_{\text {cation }} E+s_{\text {cation }} S+a_{\text {cation }} A+b_{\text {cation }} B+\right. \\
\left.l_{\text {cation }} L\right)+\sum_{\text {anion }}\left(e_{\text {anion }} E+s_{\text {anion }} S+a_{\text {anion }} A+b_{\text {anion }} B+\right. \\
\left.l_{\text {anion }} L\right)(8) \\
N=584, R^{2}=0.992, S D=0.102, F=1249.7
\end{gathered}
$$

The calculated cation-specific and anion-specific equation coefficients are listed in Table 1 . Here and elsewhere $N$ corresponds to the number of data points, $R$ denotes the correlation coefficient, SD is the standard deviation, and $F$ gives the Fisher $\mathrm{F}$ statistic. Regression analysis was performed using SPSS statistic software. ${ }^{63}$ Equation 8 is

\begin{tabular}{|c|c|c|c|c|c|c|}
\hline ion & $c$ & $e_{\text {ion }}$ & $s_{\text {ion }}$ & $a_{\text {ion }}$ & $b_{\text {ion }}$ & $l_{\text {ion }}$ \\
\hline$[\mathrm{MEI}$ & & & & 2.298 & & 0.633 \\
\hline$\left.{ }_{[\mathrm{MBIm}}\right]^{+}$ & $\begin{array}{c}-0.481 \\
(0.013)\end{array}$ & $\begin{array}{c}0.119 \\
(0.096)\end{array}$ & $\begin{array}{c}2.039 \\
(0.129)\end{array}$ & $\begin{array}{c}2.172 \\
(0.153)\end{array}$ & $\begin{array}{c}0.956 \\
(0.169)\end{array}$ & $\begin{array}{c}0.702 \\
(0.007)\end{array}$ \\
\hline$[\mathrm{MHIm}]^{+}$ & $\begin{array}{c}-0.481 \\
(0.013)\end{array}$ & $\begin{array}{c}0.048 \\
(0.090)\end{array}$ & $\begin{array}{l}1.941 \\
(0.092)\end{array}$ & $\begin{array}{c}2.165 \\
(0.116)\end{array}$ & $\begin{array}{c}0.710 \\
(0.103)\end{array}$ & $\begin{array}{c}0.785 \\
(0.007)\end{array}$ \\
\hline$[\mathrm{MOIm}]^{+}$ & $\begin{array}{c}-0.481 \\
(0.013)\end{array}$ & $\begin{array}{c}-0.297 \\
(0.138)\end{array}$ & $\begin{array}{c}1.672 \\
(0.196)\end{array}$ & $\begin{array}{c}2.152 \\
(0.239)\end{array}$ & $\begin{array}{c}0.982 \\
(0.270)\end{array}$ & $\begin{array}{c}0.871 \\
(0.009)\end{array}$ \\
\hline$\left[\mathrm{M}_{3} \mathrm{BAm}\right]^{+}$ & $\begin{array}{c}-0.481 \\
(0.013)\end{array}$ & $\begin{array}{c}0.153 \\
(0.117)\end{array}$ & $\begin{array}{c}2.070 \\
(0.134)\end{array}$ & $\begin{array}{c}2.253 \\
(0.173)\end{array}$ & $\begin{array}{c}0.797 \\
(0.174)\end{array}$ & $\begin{array}{c}0.672 \\
(0.007)\end{array}$ \\
\hline$\left[\mathrm{M}_{2} \mathrm{EIm}\right]^{+}$ & $\begin{array}{c}-0.481 \\
(0.013)\end{array}$ & $\begin{array}{c}0.239 \\
(0.120)\end{array}$ & $\begin{array}{c}2.298 \\
(0.123)\end{array}$ & $\begin{array}{l}2.047 \\
(0.157)\end{array}$ & $\begin{array}{c}0.867 \\
(0.124)\end{array}$ & $\begin{array}{c}0.635 \\
(0.012)\end{array}$ \\
\hline$[\mathrm{MBPy}]^{+}$ & $\begin{array}{c}-0.481 \\
(0.013)\end{array}$ & $\begin{array}{c}0.276 \\
(0.169)\end{array}$ & $\begin{array}{c}2.131 \\
(0.198)\end{array}$ & $\begin{array}{c}1.767 \\
(0.249)\end{array}$ & $\begin{array}{c}1.164 \\
(0.249)\end{array}$ & $\begin{array}{c}0.679 \\
(0.014)\end{array}$ \\
\hline [NEP & $\begin{array}{c}-0.481 \\
(0.013)\end{array}$ & $\begin{array}{c}0.309 \\
(0.173)\end{array}$ & $\begin{array}{c}2.334 \\
(0.163)\end{array}$ & $\begin{array}{c}2.216 \\
(0.177)\end{array}$ & $\begin{array}{c}0.901 \\
(0.136)\end{array}$ & $\begin{array}{c}0.613 \\
(0.014)\end{array}$ \\
\hline$\left[(\mathrm{Tf})_{2} \mathrm{~N}\right]^{-}$ & $\begin{array}{c}-0.481 \\
(0.013)\end{array}$ & 0.000 & 0.000 & 0.000 & 0.000 & 0.000 \\
\hline$\left[\mathrm{BF}_{4}\right]^{-}$ & $\begin{array}{c}-0.481 \\
(0.013)\end{array}$ & $\begin{array}{c}0.234 \\
(0.117)\end{array}$ & $\begin{array}{c}0.301 \\
(0.156)\end{array}$ & $\begin{array}{c}1.312 \\
(0.196)\end{array}$ & $\begin{array}{c}-0.611 \\
(0.216)\end{array}$ & $\begin{array}{c}-0.105 \\
(0.008)\end{array}$ \\
\hline$\left[\mathrm{PF}_{6}\right]$ & $\begin{array}{c}-0.481 \\
(0.013)\end{array}$ & $\begin{array}{c}-0.414 \\
(0.117)\end{array}$ & $\begin{array}{c}0.802 \\
(0.148)\end{array}$ & $\begin{array}{c}0.625 \\
(0.196)\end{array}$ & $\begin{array}{c}-0.919 \\
(0.195)\end{array}$ & $\begin{array}{c}-0.066 \\
(0.010)\end{array}$ \\
\hline$\left[\mathrm{EtSO}_{4}\right]^{-}$ & $\begin{array}{c}-0.481 \\
(0.013)\end{array}$ & $\begin{array}{r}-0.049 \\
(0.156)\end{array}$ & $\begin{array}{c}0.149 \\
(0.175)\end{array}$ & $\begin{array}{c}2.838 \\
(0.218)\end{array}$ & $\begin{array}{c}-1.073 \\
(0.212)\end{array}$ & $\begin{array}{r}-0.089 \\
(0.012)\end{array}$ \\
\hline
\end{tabular}
statistically very good and describes an experimental $\log K$
Table 1. Cation-Specific and Anion-Specific Equation Coefficients for the Abraham Model Gas-to-RTIL Correlation

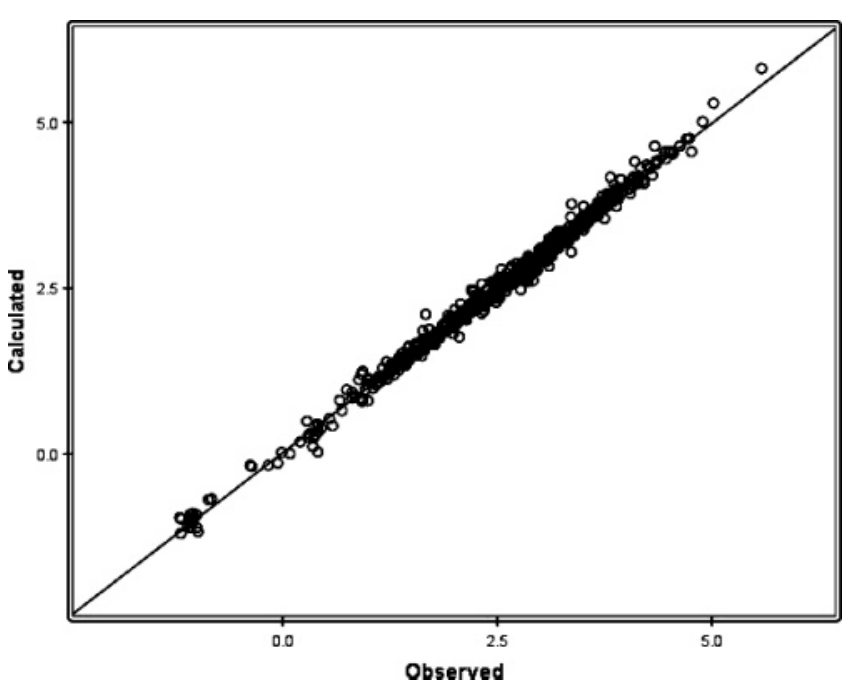

Figure 1. Comparison of experimental $\log K$ data and predicted values based on the Abraham model with the cation-specific and anion-specific equation coefficients given in Table 1 .

database that covers a $6.92 \mathrm{log}$ unit range to within a standard deviation of $0.102 \mathrm{log}$ units. The number of experimental data points for the individual ions ranges from a minimum of $31 \log K$ values for the $[\mathrm{NEP}]^{+}$cation to more than 350 $\log K$ values for the $\left[(\mathrm{Tf})_{2} \mathrm{~N}\right]^{-}$anion, which is sufficient for the regression analysis. Figure 1 depicts a plot of experimental $\log K$ data versus the calculated values based on eq 8 (each prediction calculation uses only the values for the cation and anion in the given RTIL).

As part of our data analyses we estimated how much predictive ability was likely to be lost as the result of separating the Abraham equation into cation-specific and anion-specific values. Abraham model correlations have been reported for 10 of the 15 RTILs studied here. To have a common basis for comparison, the deviations between observed and calculated values were expressed as 


$$
\mathrm{SD}=\sqrt{\frac{\left(\log K_{\mathrm{calc}}-\log K_{\mathrm{obs}}\right)^{2}}{N-6}}
$$

which is how the deviations were reported in the earlier studies. The results of our computations are summarized in Table 2. Examination of the numerical entries reveals that there is a slight loss in predictive ability due to the splitting of the equation coefficients into cation and anion values. For example, our original correlation for gas-to-([MOIm $]^{+}$$\left.[\mathrm{BF} 4]^{-}\right)$

$\log K=-0.268-0.100 \mathbf{E}+1.800 \mathbf{S}+3.224 \mathbf{A}+$ $0.453 \mathbf{B}+0.722 \mathbf{L}$

based solely on partition coefficient for 48 solutes in only $\left([\mathrm{MOIm}]^{+}\left[\mathrm{BF}_{4}\right]^{-}\right)$had a standard deviation of $\mathrm{SD}=0.104$. The correlation constructed from the $[\mathrm{MOIm}]^{+}$-specific and $\left[\mathrm{BF}_{4}\right]^{-}$-specific equation coefficients in Table 1

$$
\begin{array}{r}
\log K=-0.481+(-0.297+0.234) \mathbf{E}+(1.673+ \\
0.301) \mathbf{S}+(2.152+1.312) \mathbf{A}+(0.982-0.611) \mathbf{B}+ \\
(0.871-0.105) \mathbf{L}(11)
\end{array}
$$

has a slightly larger standard deviation of $\mathrm{SD}=0.122$ for the same 48 solutes; however, now the equation coefficients are based on partition coefficient data for solutes in other RTILs containing the $[\mathrm{MOIm}]^{+}$and/or $\left[\mathrm{BF}_{4}\right]^{-}$ions as well. It should be noted that within any reasonable error (see Table 1 ), the cation and anion values for any coefficient in eq 11 add up to the value of the coefficient in eq 10; this of course is a condition for self-consistency of our method. We have already shown that the equation coefficients in the individual RTIL correlations encode valuable information regarding the solubilizing properties of the individual RTILs. ${ }^{12,13} \mathrm{We}$ expect the cation-specific and anion-specific values to similarly provide information regarding solute-ion interactions; however, now the information should be relative to our fixed reference point of the $(\mathrm{Tf})_{2} \mathrm{~N}^{-}$anion.

The major advantage of our method is that we can make predictions for more room-temperature ionic liquids. In the past one had to have sufficient experimental data for each RTIL to develop a separate correlation equation. Generally this required finding or measuring partition coefficients of 40 or 50 solutes in the RTIL under consideration. We were able to find experimental partition coefficient data for only six solutes in 1-methyl-3-ethylimidazolium tetrafluoroborate $\left([\mathrm{MEIm}]^{+}\left[\mathrm{BF}_{4}\right]^{-}\right)$. Developing a predictive Abraham model correlation from this small number of data points is not possible. However, by combining all of the experimental data for RTILs containing either [MEIm] $]^{+}$cation or $\left[\mathrm{BF}_{4}\right]^{-}$anion we had sufficient data for calculating $[\mathrm{MEIm}]^{+}$-specific and $\left[\mathrm{BF}_{4}\right]^{-}$-specific equation coefficients. The $[\mathrm{MEIm}]^{+}$-specific and $\left[\mathrm{BF}_{4}\right]^{-}$-specific equation coefficients from Table 1 can now be put together to yield a predictive equation for $\left([\mathrm{MEIm}]^{+}\left[\mathrm{BF}_{4}\right]^{-}\right)$

$$
\begin{aligned}
\log K=-0.481+(0.158+0.234) \mathbf{E}+(2.319+ \\
0.301) \mathbf{S}+(2.298+1.312) \mathbf{A}+(1.036-0.611) \mathbf{B}+ \\
(0.633-0.105) \mathbf{L}(12)
\end{aligned}
$$

that would not have been obtainable under the earlier RTIL treatment.
Table 2. Summarized Comparison of the Descriptive Ability of

\begin{tabular}{|c|c|c|c|c|c|c|}
\hline 10 & $c$ & on & on & ion & $b_{\text {ion }}$ & $l_{\text {ion }}$ \\
\hline IE & & & & & & \\
\hline $\mathrm{ABI}$ & & & & & & \\
\hline MHI & & & & & & \\
\hline 401 & & & & & & \\
\hline $\mathrm{A}_{3} \mathrm{~B}$ & & & & & & \\
\hline $\mathrm{A}$ & & & & & & \\
\hline & & & & & & \\
\hline IFD & & & & & & \\
\hline Tf & & & & & & 0000 \\
\hline $3 F_{3}$ & & & ) & & & $\begin{array}{l}02 \\
11)\end{array}$ \\
\hline $\left.\mathrm{PF}_{6}\right]^{-}$ & $\begin{array}{r}-0.4 \\
(0.0\end{array}$ & & 0.5 & $\begin{array}{c}0.482 \\
(0.251)\end{array}$ & $\begin{array}{c}-0.663 \\
(0.261)\end{array}$ & $\begin{array}{c}-0.056 \\
(0.015)\end{array}$ \\
\hline $\left.\mathrm{tSO}_{4}\right]^{-}$ & $\begin{array}{r}-0.479 \\
(0.018)\end{array}$ & $\begin{array}{r}-0.012 \\
(0.202)\end{array}$ & $\begin{array}{c}-0.038 \\
(0.227)\end{array}$ & $\begin{array}{c}2.566 \\
(0.314)\end{array}$ & $\begin{array}{r}-0.862 \\
(0.302)\end{array}$ & $\begin{array}{c}-0.079 \\
(0.014)\end{array}$ \\
\hline
\end{tabular}
RTIL-Specific Abraham Correlation Versus Correlations Based on Cation-Specific and Anion-Specific Equation Coefficients for Gas-to-RTIL Partition Coefficients

\begin{tabular}{lcc}
\hline & \multicolumn{2}{c}{ standard deviation $(\mathrm{SD})^{a}$} \\
\cline { 2 - 3 } & RTIL-specific & ion-specific coefficient \\
\hline$\left([\mathrm{MEIm}]^{+}\left[(\mathrm{Tf})_{2} \mathrm{~N}\right]^{-}\right)$ & 0.079 & 0.083 \\
$\left(\left[\mathrm{M}{ }_{2} \mathrm{EIm}\right]^{+}\left[(\mathrm{Tf})_{2} \mathrm{~N}\right]^{-}\right)$ & 0.071 & 0.080 \\
$\left([\mathrm{MBIm}]^{+}\left[(\mathrm{Tf})_{2} \mathrm{~N}\right]^{-}\right)$ & 0.068 & 0.082 \\
$\left([\mathrm{MHIm}]^{+}\left[(\mathrm{Tf})_{2} \mathrm{~N}\right]^{-}\right)$ & 0.090 & 0.115 \\
$\left(\left[\mathrm{M}_{3} \mathrm{BAm}\right]^{+}\left[(\mathrm{Tf})_{2} \mathrm{~N}\right]^{-}\right)$ & 0.089 & 0.093 \\
$\left([\mathrm{MOIm}]^{+}\left[\mathrm{BF}_{4}\right]^{-}\right)$ & 0.104 & 0.122 \\
$\left([\mathrm{MBIm}]^{+}\left[\mathrm{PF}_{6}\right]^{-}\right)$ & 0.110 & 0.153 \\
$\left([\mathrm{BMPy}]^{+}\left[\mathrm{BF}_{4}\right]^{-}\right)$ & 0.062 & 0.071 \\
$\left.\left([\mathrm{MEIm}]^{+}[\mathrm{EtSO}]_{4}\right]^{-}\right)$ & 0.104 & 0.123 \\
$\left([\mathrm{BMIm}]^{+}\left[\mathrm{BF}_{4}\right]^{-}\right)$ & 0.085 & 0.115 \\
average $^{a}$ & 0.086 & 0.104 \\
${ }^{a} \mathrm{SD}=\sqrt{\left(\log K_{\text {calc }}-\log K_{\text {obs }}\right)^{2} / N-6 .}$ \\
\hline
\end{tabular}

Table 3. Cation-Specific and Anion-Specific Equation Coefficients for the Abraham Model Gas-to-RTIL Training Set Correlation

To further assess the predictive capability of eq 8 , we divided the 584 data points into a training set and a test set by allowing the SPSS software to randomly select half of the experimental data points for each RTIL. The selected data points became the training set, and the compounds that were left served as the test set. Analysis of the experimental data in the training set gave the cation-specific and anionspecific equation coefficients listed in Table 3, with $N=$ $292, \mathrm{SD}=0.094, R^{2}=0.994$, and $F=736.0$. The training set equation coefficients were then used to predict $\log K$ values for the 292 compounds in the test set. For the predicted and experimental values we find $\mathrm{SD}=0.086$, average absolute error $(\mathrm{AAE})=0.088$, and average error $(\mathrm{AE})=0.012$. There is therefore very little bias in the predictions using eq 8 with $\mathrm{AE}$ equal to $0.012 \log$ units.

The 571 experimental water-to-RTIL partition coefficients were analyzed in similar fashion according to

$$
N=571, R^{2}=0.994, \mathrm{SD}=0.135, F=1455.4
$$




$$
\begin{array}{r}
\log P=c+\sum_{\text {cation }}\left(e_{\text {cation }} E+s_{\text {cation }} S+a_{\text {cation }} A+b_{\text {cation }} B+\right. \\
\left.v_{\text {cation }} V\right)+\sum_{\text {anion }}\left(e_{\text {anion }} \mathrm{E}+\mathrm{s}_{\text {anion }} S+a_{\text {anion }} A+\right. \\
\left.b_{\text {anion }} B+v_{\text {anion }} V\right)(13)
\end{array}
$$

The calculated cation-specific and anion-specific equation coefficients are given in Table 4, along with their respective standard deviations. Equation 13 is statistically very good with a standard deviation of $0.135 \log$ units for a $\log P$ data set that covers a range of $7.67 \log$ units. See Figure 2 for a plot of the calculated values of $\log P$ based on eq 13 against the observed values.

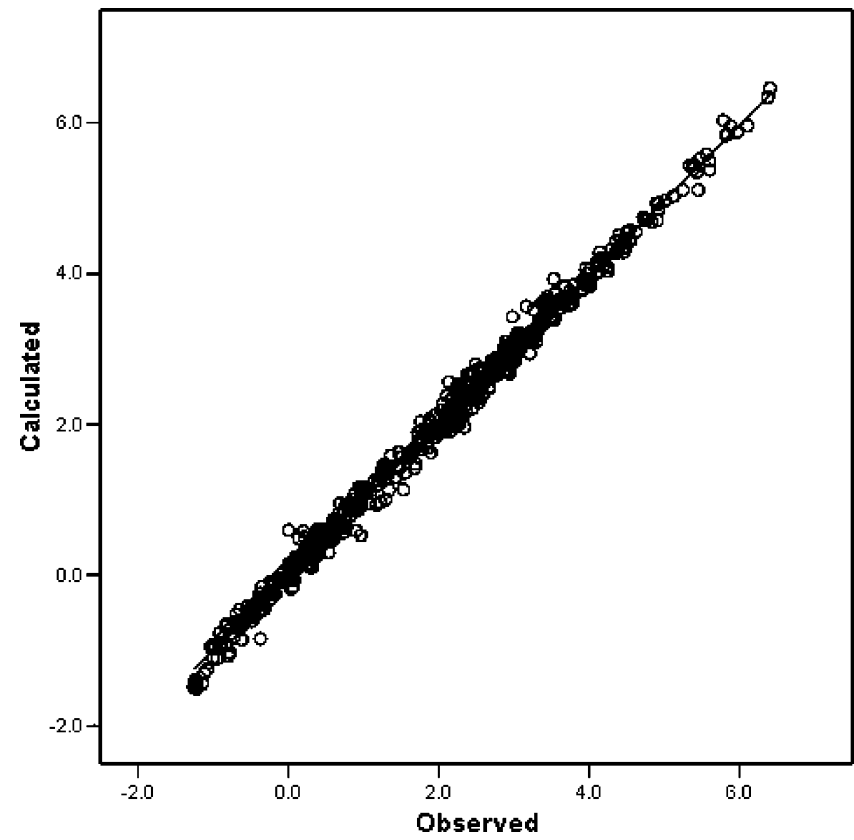

Figure 2. Comparison of experimental $\log P$ data and predicted values based on the Abraham model with the cation-specific and anion-specific equation coefficients given in Table 4 .

\begin{tabular}{|c|c|c|c|c|c|c|}
\hline 101 & 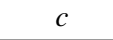 & ion & ion & $a_{\text {ion }}$ & $b_{\mathrm{io}}$ & ion \\
\hline MEI & & & & & & \\
\hline MBI & & & & & & \\
\hline QH & & & & & & \\
\hline IOm & & & & & & \\
\hline $\mathrm{M}_{3} \mathrm{~B}$ & & & & & & \\
\hline $\mathrm{M}_{2} \mathrm{E}$ & & & & & & \\
\hline MDDut & & & & & & \\
\hline JED] & & & & $\begin{array}{r}-1 \\
(0\end{array}$ & $\begin{array}{r}-3 . \\
(0 .\end{array}$ & \\
\hline Tf & & & & & & \\
\hline $\mathrm{F}_{3}$ & & & & & & (0) \\
\hline PE。 & & & & & & $\begin{array}{c}-0.256 \\
(0.039)\end{array}$ \\
\hline $\left.\mathrm{tSO}_{4}\right]$ & $\begin{array}{c}-0.026 \\
(0.023)\end{array}$ & $\begin{array}{c}-0.311 \\
(0.202)\end{array}$ & $\begin{array}{c}0.294 \\
(0.234)\end{array}$ & $\begin{array}{c}3.055 \\
(0.288)\end{array}$ & $\begin{array}{r}-1.349 \\
(0.281)\end{array}$ & $\begin{array}{c}-0.280 \\
(0.047)\end{array}$ \\
\hline
\end{tabular}

Table 4. Cation-Specific and Anion-Specific Equation Coefficients for the Abraham Model Water-to-RTIL Correlation

\begin{tabular}{|c|c|c|c|c|c|c|}
\hline & $c$ & on & ion & $a_{\text {ion }}$ & $b_{\mathrm{io}}$ & on \\
\hline $\mathrm{MFI}$ & & & & & & \\
\hline $\mathrm{ABI}$ & & & & & & \\
\hline AHI & & & & & & \\
\hline & & & & & & \\
\hline $\mathrm{A}_{3} \mathrm{~B}$ & & & & & & \\
\hline$M$ & & & & & & \\
\hline & & & & & & \\
\hline & & & & & & $\begin{array}{l}3 . \\
(0.1\end{array}$ \\
\hline$\Gamma f$ & $\begin{array}{r}-0.0 \\
(0.0\end{array}$ & & & & & \\
\hline E. & & & & & & \\
\hline $\mathrm{F}$ & & & & & & $\begin{array}{r}-0.267 \\
(0.051)\end{array}$ \\
\hline $\left.\mathrm{tSO}_{4}\right]^{-}$ & $\begin{array}{r}-0.029 \\
(0.030)\end{array}$ & $\begin{array}{c}-0.221 \\
(0.293)\end{array}$ & $\begin{array}{r}-0.100 \\
(0.406)\end{array}$ & $\begin{array}{c}2.404 \\
(0.476)\end{array}$ & $\begin{array}{c}-0.593 \\
(0.518)\end{array}$ & $\begin{array}{c}-0.281 \\
(0.065)\end{array}$ \\
\hline
\end{tabular}

Table 5. Cation-Specific and Anion-Specific Equation Coefficients for the Abraham Model Water-to-RTIL Training Set Correlation

Table 6. Summarized Comparison of the Descriptive Ability of RTIL-Specific Abraham Correlation Versus Correlations Based on Cation-Specific and Anion-Specific Equation Coefficients for Water-to-RTIL Partition Coefficients

\begin{tabular}{lcc}
\hline & \multicolumn{2}{c}{ standard deviation $(\mathrm{SD})^{a}$} \\
\cline { 2 - 3 } & RTIL-specific & ion-specific coefficient \\
\hline$\left([\mathrm{MEIm}]^{+}\left[(\mathrm{Tf})_{2} \mathrm{~N}\right]^{-}\right)$ & 0.127 & 0.127 \\
$\left(\left[\mathrm{M}{ }_{2} \mathrm{EIm}\right]^{+}\left[(\mathrm{Tf})_{2} \mathrm{~N}\right]^{-}\right)$ & 0.131 & 0.131 \\
$\left([\mathrm{MBIm}]^{+}\left[(\mathrm{Tf})_{2} \mathrm{~N}\right]^{-}\right)$ & 0.095 & 0.124 \\
$\left([\mathrm{MHIm}]^{+}\left[(\mathrm{Tf})_{2} \mathrm{~N}\right]^{-}\right)$ & 0.136 & 0.143 \\
$\left(\left[\mathrm{M}_{3} \mathrm{BAm}\right]^{+}\left[(\mathrm{Tf})_{2} \mathrm{~N}\right]^{-}\right)$ & 0.089 & 0.105 \\
$\left([\mathrm{MOIm}]^{+}\left[\mathrm{BF}_{4}\right]^{-}\right)$ & 0.131 & 0.143 \\
$\left([\mathrm{MBIm}]^{+}\left[\mathrm{PF}_{6}\right]^{-}\right)$ & 0.162 & 0.162 \\
$\left([\mathrm{BMPy}]^{+}\left[\mathrm{BF}_{4}\right]^{-}\right)$ & 0.141 & 0.141 \\
$\left([\mathrm{MEIm}]^{+}\left[\mathrm{EtSO}_{4}\right]^{-}\right)$ & 0.138 & 0.148 \\
$\left([\mathrm{BMIm}]^{+}\left[\mathrm{BF}_{4}\right]^{-}\right)$ & 0.142 & 0.160 \\
& 0.129 & 0.138 \\
& & \\
${ }^{a} \mathrm{SD}=\sqrt{\left(\log P_{\text {calc }}-\log P_{\text {obs }}\right)^{2} / N-6 .}$ & \\
\hline
\end{tabular}

The derived water-to-RTIL correlation was validated by dividing the 571 experimental data points into a training set and a test set as before. Analysis of the experimental $\log P$ data in the training set gave the cation-specific and anionspecific equation coefficients that are tabulated in Table 5, with $N=286, \mathrm{SD}=0.120, R^{2}=0.994$, and $F=746.6$. The training set equation was then used to predict $\log P$ values for the 285 compounds in the test set. For the predicted and experimental values we find that $\mathrm{SD}=0.113$, $\mathrm{AAE}=0.131$, and $\mathrm{AE}=0.041$. There is therefore very little bias in the predictions using eq 13 with $\mathrm{AE}$ equal to 0.041 $\log$ units.

Finally, water-to-RTIL correlations have been reported in the literature for 10 ionic solvents. In Table 6 we have assembled the deviations between observed and calculated values based on eq 13 and the deviations that were reported at the time each RTIL-specific correlation was published. All tabulated deviations were calculated using eq 6. Examination of the tabulated values indicates that there is a small loss in predictive ability due to splitting of the solvent 
equation coefficients into cation and anion values, an average standard deviation of SD $=0.129$ for the RTIL-specific correlations versus $\mathrm{SD}=0.136$ for correlations using the cation-specific and anion-specific coefficients. The benefits associated with being able to construct additional predictive correlations simply by combining the tabulated cationspecific and anion-specific equation coefficients should more than outweigh the slight loss in predictive accuracy noted above. The 8 sets of cation-specific equation coefficients and 4 sets of anion-specific equation coefficients can be combined to yield predictive equations for 32 different RTILs. This more than triples the number of predictive Abraham model equations that were available prior to this study. The cation and anion contributions to the coefficients in eqs 8 and 13 represent the (relative) properties of ions in bulk ionic liquids. They should not be confused with the (absolute) properties of ions that we have previously obtained ${ }^{64}$ and which refer to single isolated ions in solvents.

Supporting Information Available: Gas-to-RTIL and water-to-RTIL partition coefficient data for organic and gaseous solutes dissolved in 16 room-temperature ionic liquids and numerical values of the solute descriptors for the compounds studied available as an Excel spreadsheet. This material is available free of charge via the Internet at http:// pubs.acs.org.

\section{REFERENCES AND NOTES}

(1) Park, S.; Kazlauskas, R. J. Biocatalysis in ionic liquids-advantages beyond green technology. Curr. Opin. Biotechnol. 2003, 14, 432437.

(2) Viswanathan, G.; Murugesan, S.; Pushparaj, V.; Nalamasu, O.; Ajayan, P. M.; Linhardt, R. J. Preparation of Biopolymer Fibers by Electrospinning from Room Temperature Ionic Liquids. Biomacromolecules 2006, 7, 415-418.

(3) Murugesan, S.; Linhardt, R. J. Ionic liquids in carbohydrate chemistry - current trends and future directions. Curr. Org. Synth. 2005, 2, 437451.

(4) Jaitely, V.; Florence, A. T. 1-Alkyl-3-methyl-imidazole hexafluorophosphate water-immiscible ionic liquids as reservoirs for controlled release of drugs. Abstracts of Papers, 226th ACS National Meeting, New York, United States, September 7-11, 2003.

(5) Planeta, J.; Karasek, P.; Roth, M. Distribution of sulfur-containing aromatics between $[\mathrm{hmim}]\left[\mathrm{Tf}_{2} \mathrm{~N}\right]$ and supercritical $\mathrm{CO}_{2}$ : A case study for deep desulfurization of oil refinery streams by extraction with ionic liquids. Green Chem. 2006, 8, 70-77.

(6) Khodadoust, A. P.; Chandrasekaran, S.; Dionysiou, D. D. Preliminary assessment of imidazolium-based room-temperature ionic liquids for extraction of organic contaminants from soils. Environ. Sci. Technol. 2006, 40, 2339-2345.

(7) Reetz, M. T.; Wiesenhoefer, W.; Francio, G.; Leitner, W. Biocatalysis in ionic liquids: batchwise and continuous flow processes using supercritical carbon dioxide as the mobile phase. Chem. Commun. 2002, 992-993.

(8) Poole, C. F. Chromatographic and spectroscopic methods for the determination of solvent properties of room temperature ionic liquids. J. Chromatogr. A 2004, 1037, 49-82.

(9) Chiappe, C.; Pieraccini, D. Ionic liquids: solvent properties and organic reactivity. J. Phys. Org. Chem. 2005, 18, 275-297.

(10) Eike, D. M.; Brennecke, J. F.; Maginn, E. J. Predicting infinite-dilution activity coefficients of organic solutes in ionic liquids. Ind. Eng. Chem. Res. 2004, 43, 1039-1048.

(11) Tämm, K.; Burk, P. QSPR analysis for infinite dilution activity coefficients of organic compounds. J. Mol. Model. 2006, 12, 417421.

(12) Acree, W. E., Jr.; Abraham, M. H. The analysis of solvation in ionic liquids and organic solvents using the Abraham linear free energy relationship. J. Chem. Technol. Biotechnol. 2006, 81, 1441-1446. [Erratum, 2006, 81, 1722 (2006)].

(13) Abraham, M. H.; Acree, W. E.; Jr. Comparative analysis of solvation and selectivity in room temperature ionic liquids using the Abraham linear free energy relationship. Green Chem. 2006, 8, 906-915.
(14) Mintz, C.; Acree, W. E., Jr. Partition coefficient correlations for transfer of solutes from the gas phase and from water to room temperature ionic liquids. Phys. Chem. Liq. Manuscript accepted for publication.

(15) Abraham, M. H.; Zissimos, A. M.; Huddleston, J. G.; Willauer, H. D.; Rogers, R. D.; Acree, W. E.; Jr. Some novel liquid partitioning systems: water-ionic liquids and aqueous biphasic systems. Ind. Eng Chem. Res. 2003, 42, 413-418.

(16) Sumartschenkowa, I. A.; Verevkin, S. P.; Vasiltsova, T. V.; Bich, E.; Heintz, Andreas;, Shevelyova, M. P.; Kabo, G. J. Experimental study of thermodynamic properties of mixtures containing ionic liquid 1-ethyl-3-methylimidazolium ethyl sulfate using gas-liquid chromatography and transpiration method. J. Chem. Eng. Data 2006, 51, 2138-2144.

(17) Shiflett, M. B.; Yokozeki, A. Gaseous absorption of fluoromethane, fluoroethane, and 1,1,2,2-tetrafluoroethane in 1-butyl-3-methylimidazolium hexafluorophosphate. Ind. Eng. Chem. Res. 2006, 45, 63756382.

(18) Zhou, Q.; Wang, L.-S. Activity coefficients at infinite dilution of alkanes, alkenes, and alkylbenzenes in 1-butyl-3-methylimidazolium tetrafluoroborate using gas-liquid chromatography. J. Chem. Eng. Data 2006, 51, 1698-1701

(19) Foco, G. M.; Bottini, S. B.; Quezada, N.; De la Fuente, J. C.; Peters, C. J. Activity coefficients at infinite dilution in 1-alkyl-3-methylimidazolium tetrafluoroborate ionic liquids. J. Chem. Eng. Data 2006 51, 1088-1091.

(20) Shiflett, M. B.; Yokozeki, A. Solubility and diffusivity of hydrofluorocarbons in room-temperature ionic liquids. AIChE J. 2006, 52, 1205-1219.

(21) Safarov, J.; Verevkin, S. P.; Bich, E.; Heintz, A. Vapor pressures and activity coefficients of $n$-alcohols and benzene in binary mixtures with 1-methyl-3-butylimidazolium octylsulfate and 1-methyl-3-octylimidazolium tetrafluoroborate. J. Chem. Eng. Data 2006, 51, 518-525.

(22) Heintz, A.; Verevkin, S. P.; Ondo, D. Thermodynamic properties of mixtures containing ionic liquids. 8 . Activity coefficients at infinite dilution of hydrocarbons, alcohols, esters, and aldehydes in 1-hexyl3-methylimidazolium bis(trifluoromethylsulfonyl)imide using gasliquid chromatography. J. Chem. Eng. Data 2006, 51, 434-437.

(23) Heintz, A.; Vasiltsova, T. V.; Safarov, J.; Bich, E.; Verevkin, S. P. Thermodynamic properties of mixtures containing ionic liquids. 9 Activity coefficients at infinite dilution of hydrocarbons, alcohols, esters, and aldehydes in trimethylbutylammonium bis(trifluoromethylsulfonyl)imide using gas-liquid chromatography and static method. J. Chem. Eng. Data 2006, 51, 648-655.

(24) Vasiltsova, T. V.; Verevkin, S. P.; Bich, E.; Heintz, A.; Bogel-Lukasik, R.; Domanska, U. Thermodynamic properties of mixtures containing ionic liquids. 7. Activity coefficients of aliphatic and aromatic esters and benzylamine in 1-methyl-3-ethylimidazolium bis(trifluoromethylsulfonyl)imide using the transpiration method. J. Chem. Eng. Data 2006, 51, 213-218

(25) Letcher, T. M.; Marciniak, A.; Marciniak, M.; Domanska, U. Activity coefficients at infinite dilution measurements for organic solutes in the ionic liquid 1-hexyl-3-methyl-imidazolium bis(trifluoromethylsulfonyl)-imide using g.l.c. at $\mathrm{T}=(298.15,313.15$, and 333.15$) \mathrm{K} . J$. Chem. Thermodyn. 2005, 37, 1327-1331.

(26) Heintz, A.; Verevkin, S. P. Thermodynamic properties of mixtures containing ionic liquids. 6. Activity coefficients at infinite dilution of hydrocarbons, alcohols, esters, and aldehydes in 1-methyl-3-octylimidazolium tetrafluoroborate using gas-liquid chromatography. $J$. Chem. Eng. Data 2005, 50, 1515-1519.

(27) Heintz, A.; Casas, L. M.; Nesterov, I. A.; Emel'yanenko, V. N.; Verevkin, S. P. Thermodynamic properties of mixtures containing ionic liquids. 5. Activity coefficients at infinite dilution of hydrocarbons, alcohols, esters, and aldehydes in 1-methyl-3-butylimidazolium bis(trifluoromethylsulfonyl)imide using gas-liquid chromatography. $J$. Chem. Eng. Data 2005, 50, 1510-1514.

(28) Kato, R.; Gmehling, J. Systems with ionic liquids: Measurement of VLE and data and prediction of their thermodynamic behavior using original UNIFAC, mod. UNIFAC(Do) and COSMO-RS(Ol). J. Chem. Thermodyn. 2005, 37, 603-619.

(29) Kato, R.; Gmehling, J. Measurement and correlation of vapor- liquid equilibria of binary systems containing the ionic liquids [EMIM] [ $\left(\mathrm{CF}_{3}\right.$ $\left.\left.\mathrm{SO}_{2}\right)_{2} \mathrm{~N}\right],[\mathrm{BMIM}]\left[\left(\mathrm{CF}_{3} \mathrm{SO}_{2}\right)_{2} \mathrm{~N}\right]$, [MMIM] $\left.\left(\mathrm{CH}_{3}\right)_{2} \mathrm{PO}_{4}\right]$ and oxygenated organic compounds respectively water. Fluid Phase Equilib. 2005 $231,38-43$.

(30) Vasiltsova, T. V.; Verevkin, S. P.; Bich, E.; Heintz, A.; Bogel-Lukasik, R.; Domanska, U. Thermodynamic properties of mixtures containing ionic liquids. Activity coefficients of ethers and alcohols in 1-methyl3-ethylimidazolium bis(trifluoromethylsulfonyl)imide using the transpiration method. J. Chem. Eng. Data 2005, 50, 142-148.

(31) Kato, R.; Gmehling, J. Activity coefficients at infinite dilution of various solutes in the ionic liquids $[\mathrm{MMIM}]^{+}\left[\mathrm{CH}_{3} \mathrm{SO}_{4}\right]^{-},[\mathrm{MMIM}]^{+}\left[\mathrm{CH}_{3} \mathrm{O}\right.$ $\left.\mathrm{C}_{2} \mathrm{H}_{4} \mathrm{SO}_{4}\right]^{-},[\mathrm{MMIM}]^{+}\left[\left(\mathrm{CH}_{3}\right)_{2} \mathrm{PO}_{4}\right]^{-},\left[\mathrm{C}_{5} \mathrm{H}_{5} \mathrm{NC}_{2} \mathrm{H}_{5}\right]^{+}\left[\left(\mathrm{CF}_{3} \mathrm{SO}_{2}\right)_{2} \mathrm{~N}\right]^{-}$ 
and $\left[\mathrm{C}_{5} \mathrm{H}_{5} \mathrm{NH}\right]^{+}\left[\mathrm{C}_{2} \mathrm{H}_{5} \mathrm{OC}_{2} \mathrm{H}_{4} \mathrm{OSO}_{3}\right]^{-}$. Fluid Phase Equilib. 2004, 226 , $37-44$.

(32) Deenadayalu, N.; Letcher, T. M.; Reddy, P. Determination of activity coefficients at infinite dilution of polar and nonpolar solutes in the ionic liquid 1-ethyl-3-methyl-imidazolium bis(trifluoromethylsulfonyl)imidate using gas-liquid chromatography at the temperature 303.15 K or 318.15 K. J. Chem. Eng. Data 2005, 50, 105-108.

(33) Letcher, T. M.; Soko, B.; R., P.; Deenadayalu, N. Determination of activity coefficients at infinite dilution of solutes in the ionic liquid 1-hexyl-3-methylimidazolium tetrafluoroborate using gas-liquid chromatography at the temperatures $298.15 \mathrm{~K}$ and $323.15 \mathrm{~K}$. J. Chem. Eng. Data 2003, 48, 1587-1590.

(34) Letcher, T. M.; Soko, B.; Ramjugernath, D.; Deenadayalu, N.; Nevines, A.; Naicker, P. K. Activity coefficients at infinite dilution of organic solutes in 1-hexyl-3-methylimidazolium hexafluorophosphate from gasliquid chromatography. J. Chem. Eng. Data 2003, 48, 708-711.

(35) Krummen, M.; Wasserscheid, P.; Gmehling, J. Measurement of activity coefficients at infinite dilution in ionic liquids using the dilutor technique. J. Chem. Eng. Data 2002, 47, 1411-1417.

(36) Heintz, A.; Kulikov, D. V.; Verevkin, S. P. Thermodynamic properties of mixtures containing ionic liquids. Activity coefficients at infinite dilution of polar solutes in 4-methyl-N-butylpyridinium tetrafluoroborate using gas-liquid chromatography. J. Chem. Thermodyn. 2002, 34, $1341-1347$

(37) Heintz, A.; Kulikov, D. V.; Verevkin, S. P. Thermodynamic properties of mixtures containing ionic liquids. 2. Activity coefficients at infinite dilution of hydrocarbons and polar solutes in 1-methyl-3-ethylimidazolium bis(trifluoromethylsulfonyl)amide and in 1,2-dimethyl3-ethylimidazolium bis(trifluoromethylsulfonyl) amide using gas-liquid chromatography. J. Chem. Eng. Data 2002, 47, 894-899.

(38) Heintz, A.; Kulikov, D. V.; Verevkin, S. P. Thermodynamic properties of mixtures containing ionic liquids. 1. Activity coefficients at infinite dilution of alkanes, alkenes, and alkylbenzenes in 4-methyl-Nbutylpyridinium tetrafluoroborate using gas-liquid chromatography. J. Chem. Eng. Data 2001, 46, 1526-1529.

(39) Camper, D.; Becker, C.; Koval, C.; Noble, R. Diffusion and solubility measurements in room temperature ionic liquids. Ind. Eng. Chem. Res. 2006, 45, 445-450.

(40) Camper, D.; Becker, C.; Koval, C.; Noble, R. Low pressure hydrocarbon solubility in room temperature ionic liquids containing imidazolium rings interpreted using regular solution theory. Ind. Eng. Chem. Res. 2005, 44, 1928-1933.

(41) Anderson, J. L.; Dixon, J. K.; Maginn, E. J.; Brennecke, J. F. Measurement of $\mathrm{SO}_{2}$ solubility in ionic liquids. J. Phys. Chem. B 2006, 110, 15059-15062.

(42) Kumelan, J.; Perez-Salado, Kamps, A.; Tuma, D.; Maurer, G. Solubility of $\mathrm{CO}_{2}$ in the ionic liquids $[\mathrm{bmim}]\left[\mathrm{CH}_{3} \mathrm{SO}_{4}\right]$ and $[\mathrm{bmim}]\left[\mathrm{PF}_{6}\right] . J$. Chem. Eng. Data 2006, 51, 1802-1807.

(43) Lee, B.-C.; Outcalt, S. L. Solubilities of gases in the ionic liquid 1-nbutyl-3-methylimidazolium bis(trifluoromethylsulfonyl)imide. J. Chem. Eng. Data 2006, 51, 892-897.

(44) Jacquemin, J.; Costa, Gomes, M. F.; Husson, P.; Majer, V. Solubility of carbon dioxide, ethane, methane, oxygen, nitrogen, hydrogen, argon, and carbon monoxide in 1-butyl-3-methylimidazolium tetrafluoroborate between temperatures $283 \mathrm{~K}$ and $343 \mathrm{~K}$ and at pressures close to atmospheric. J. Chem. Thermodyn. 2006, 38, 490-502.

(45) Jacquemin, J.; Husson, P.; Majer, V.; Gomes, M. F. C. Low-pressure solubilities and thermodynamics of solvation of eight gases in 1-butyl3-methylimidazolium hexafluorophosphate. Fluid Phase Equilib. 2006, 240, 87-95.

(46) Anthony, J. L.; Anderson, J. L.; Maginn, E. J.; Brennecke, J. F. Anion effects on gas solubility in ionic liquids. J. Phys. Chem. B 2005, 109, 6366-6374.

(47) Ohlin, C. A.; Dyson, P. J.; Laurenczy, G. Carbon monoxide solubility in ionic liquids: determination, prediction and relevance to hydroformylation. Chem. Commun. 2004, 1070-1071.
(48) Kumelan, J.; Perez-Salado, Kamps, A.; Tuma, D.; Maurer, G. Solubility of $\mathrm{CO}_{2}$ in the ionic liquid $[\mathrm{hmim}]\left[\mathrm{Tf}_{2} \mathrm{~N}\right]$. J. Chem. Thermodyn. 2006 $38,1396-1401$

(49) Baltus, R. E.; Culbertson, B. H.; Dai, S.; Luo, H.; DePaoli, D. W. Low-pressure solubility of carbon dioxide in room-temperature ionic liquids measured with a quartz crystal microbalance. J. Phys. Chem. B 2004, 108, 721-727.

(50) Zhou, Q.; Wang, L.-S.; Wu, J.-S.; Li, M.-Y. Activity coefficients at infinite dilution of polar solutes in 1-butyl-3-methylimidazolium tetrafluoroborate using gas-liquid chromatography. J. Chem. Eng. Data 2007, 52, 131-134.

(51) Letcher, T. M.; Soko, B.; Ramjugernath, D.; Deenadayalu, N.; Nevines, A.; Naicker, P. K. Activity coefficients at infinite dilution of organic solutes in 1-hexyl-3-methylimidazolium hexafluorophosphate from gas-liquid chromatography. J. Chem. Eng. Data 2003, 48, 708711.

(52) Verevkin, S. P.; Vasiltsova, T. V.; Bich, E.; Heintz, A. Thermodynamic properties of mixtures containing ionic liquids Activity coefficients of aldehydes and ketones in 1-methyl-3-ethyl-imidazolium bis(trifluoromethylsulfonyl)imide using the transpiration method. Fluid Phase Equilib. 2004, 218, 165-175.

(53) Abraham, M. H. Scales of hydrogen bonding: Their construction and application to physicochemical and biochemical processes. Chem. Soc. Rev. 1993, 22, 73-83.

(54) Abraham, M. H.; Ibrahim, A.; Zissimos, A. M. The determination of sets of solute descriptors from chromatographic measurements. $J$. Chromatogr. A 2004, 1037, 29-47.

(55) Abraham, M. H.; Acree, W. E., Jr. Correlation and prediction of partition coefficients between the gas phase and water, and the solvents dodecane and undecane. New J. Chem. 2004, 28, 1538-1543.

(56) Abraham, M. H.; Acree, W. E., Jr. The correlation and prediction of butane/water and gas/butane partition coefficients. Can. J. Chem. Eng. 2005, 83, 362-365.

(57) PharmaAlgorithms Inc. PharmaAlgorithms, ADME Boxes, Version 2.2; PharmaAlgorithms Inc.: Toronto, Ontario, Canada.

(58) Abraham, M. H.; Green, C. E.; Acree, W. E., Jr.; Hernandez, C. E.; Roy, L. E. Descriptors for solutes from the solubility of solids: transstilbene as an example. J. Chem. Soc., Perkin Trans. 2 1998, 26772682.

(59) Green, C. E.; Abraham, M. H.; Acree, W. E., Jr.; De Fina, K. M. Sharp, T. L. Solvation descriptors for pesticides from the solubility of solids: diuron as an example. Pest Manage. Sci. 2000, 56, 10431053.

(60) Zissimos, A. M.; Abraham, M. H.; Du, C. M.; Valko, K.; Bevan, C.; Reynolds, D.; Wood, J.; Tam, K. Y. Calculation of Abraham descriptors from experimental data from seven HPLC systems; evaluation of five different methods of calculation. J. Chem. Soc., Perkin Trans. 2 2002, 2001-2010.

(61) Zissimos, A. M.; Abraham, M. H.; Barker, M. C.; Box, K. J.; Tam, K. Y. Calculation of Abraham descriptors from solvent-water partition coefficients in four different systems; evaluation of different methods of calculation. J. Chem. Soc., Perkin Trans. 2 2002, 470-477.

(62) McGowan, J. C.; Abraham, M. H. The use of characteristic volumes to measure cavity terms in reversed phase liquid chromatography. Chromatographia 1987, 23, 243-246.

(63) SPSS, Data Mining, Statistical Analysis Software, Predictive Applications, Predictive Analytics, Decision Support Systems. http://www.spss.com (accessed March 6, 2007).

(64) Abraham, M. H.; Zhao, Y. H. Determination of solvation descriptors for ionic species: hydrogen bond acidity and basicity. J. Org. Chem. 2004, 69, 4677- 4685 .

\section{CI7000428}

